\title{
CORRECTION
}

View Article Online

View Journal I View Issue

Check for updates

Cite this: RSC Adv., 2021, 11, 4373

DOI: 10.1039/dOra90141e

rsc.li/rsc-advances

\section{Correction: Triple-negative breast cancer suppressive activities, antioxidants and pharmacophore model of new acylated rhamnopyranoses from Premna odorata}

\author{
Abeer H. Elmaidomy, ${ }^{a}$ Rabab Mohammed, ${ }^{a}$ Asmaa I. Owis, ${ }^{a}$ Mona H. Hetta, ${ }^{b}$

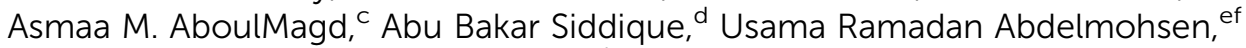 \\ Mostafa E. Rateb, ${ }^{\text {ag }}$ Khalid A. El Sayed ${ }^{d}$ and Hossam M. Hassan*a \\ Correction for 'Triple-negative breast cancer suppressive activities, antioxidants and pharmacophore model \\ of new acylated rhamnopyranoses from Premna odorata' by Abeer H. Elmaidomy et al., RSC Adv., 2020, 10, \\ 10584-10598. DOI: 10.1039/D0RA01697G
}

The authors regret that the name of the author Asmaa I. Owis was incorrectly spelled as Asmsaa I. Owis in the original article. The correct author list is as displayed in this document.

The Royal Society of Chemistry apologises for these errors and any consequent inconvenience to authors and readers.

\footnotetext{
aDepartment of Pharmacognosy, Faculty of Pharmacy, Beni-Suef University, Beni-Suef 62514, Egypt. E-mail: hossam.abdelazeem@pharm.bsu.edu.eg ${ }^{b}$ Department of Pharmacognosy, Faculty of Pharmacy, Fayoum University, Fayoum 63514, Egypt 'Department of Pharmaceutical Chemistry, Faculty of Pharmacy, Nahda University, Beni-Suef 62514, Egypt ${ }^{d}$ School of Basic Pharmaceutical and Toxicological Sciences, College of Pharmacy, University of Louisiana at Monroe, Monroe, LA 71201, USA ${ }^{e}$ Department of Pharmacognosy, Faculty of Pharmacy, Minia University, Minia 61519, Egypt ${ }^{f}$ Department of Pharmacognosy, Faculty of Pharmacy, Deraya University, Minia 61111, Egypt ${ }^{g}$ School of Computing, Engineering and Physical Sciences, University of the West of Scotland, PA1 2BE Paisley, UK
} 